\title{
Agricultura Urbana e Infraestrutura Sustentável: A situação no Brasil e em Portugal
}

Urban Agriculture and Sustainable Infrastructure: The situation in Brazil and Portugal

Agricultura urbana y infraestrutuctura sustentable: la situacion en Brasil y en Portugal

Juan José Mascaró

Professor Doutor Arquiteto, UPF, Brasil. juan@upf.br

\section{Bianca Vargas Acunha} Graduanda em Arquitetura, UPF, Brasil. bianca_acunha@hotmail.com

Natalia Pasini Paggotto Graduanda em Arquitetura, UPF, Brasil. nataliapaggotto@hotmail.com 


\section{RESUMO}

Agricultura dentro das cidades tem sido reconhecida por sua contribuição para a sustentabilidade urbana, devido à capacidade de integrar aspectos sociais, econômicos e ambientais que foi inserida na abordagem de serviços de ecossistemas. A relação entre as cidades e agricultura têm sido o principal motivador na segregação apesar de sua dependência mútua. Em Portugal como no Brasil essa segregação de espaço significou também a segregação de funções e metas de gestão além da segregação de políticas: as políticas agrícolas por um lado e as políticas urbanas por outro, tratadas separadamente nos diferentes compartimentos institucionais. Este artigo optou por se concentrar em explorar a variedade de situação e a diversidade de pessoas que trabalham na agricultura urbana na busca por definir a base para a integração mais flexível no processo de planejamento urbano em Portugal e no Brasil. Assim, pretende proporcionar insights sobre as motivações atuais dos agricultores urbanos e suas expectativas em relação ao futuro destes espaços. No caso do Brasil, à procura de elementos de comparação que denotam diferentes aspectos das áreas onde a agricultura surgiu em algumas cidades brasileiras, suas políticas públicas e a relação com os cidadãos apontam resultados interessantes e promissores. É necessário pensar uma nova abordagem para lidar com a nova situação social nos dois países. Fortalecer organizações sociais nascidos na web como também as associações coletivas de bairros afim de criar vínculos e ações efetivas para tornar a agricultura urbana uma realidade urbana e um elemento integrante da infraestrutura verde sustentável.

PALAVRAS-CHAVE: Sustentabilidade - Agricultura - Infraestrutura

\section{ABSTRACT}

Agriculture within cities has been recognized for its contribution to urban sustainability, owing to the ability to integrate social, economic and environmental aspects that has been framed with the approach of ecosystem services. The relationship between cities and agriculture has been the main motivator in segregation despite their mutual dependence. In Portugal and Brazil, this segregation of space also meant the segregation of functions and management goals beyond the segregation of policies: agricultural policies on the one hand and urban policies on the other hand, treated separately in the different institutional compartments. This paper has chosen to focus on exploring the variety of situation and the diversity of people working in urban agriculture in the search for the basis for more flexible integration in the urban planning process in Portugal and Brazil. Thus, it aims to provide insight into the current motivations of urban farmers and their expectations regarding the future of these spaces. In the case of Brazil, in search of elements of comparison that denote different aspects of the areas where agriculture appeared in some Brazilian cities, its public policies and the relation with the citizens point to interesting and promising results. It is necessary to think of a new approach to dealing with the new social situation in the two countries. Strengthen social organizations born on the web as well as collective neighborhood associations in order to create effective links and actions to make urban agriculture an urban reality and an integral element of sustainable green infrastructure.

KEYWORDS: Sustainability - Agriculture - Infrastructure

\section{RESUMEN}

La agricultura dentro de las ciudades ha sido reconocida por su contribución para la sustentabilidad urbana, por su capacidad de integrar características sociales, económicas y ambientales que han sido enfocadas en el entendimento de los servicios de ecosistemas. La relacion entre las ciudades y la agricultura ha cido el principal motivo en la segregacion aun de su mutua dependencia. En Portugal como en Brasil esa segregación de espacios significativos tambien muestra la segregación de funciones y metas de gestión ademas de segregacion de politicas: las politicas agricolas de una manera y las politicas urbanas por otra son tratadas de forma

separadas en diferentes compartimentos institucionales. Este articulo decidio concentrarse en explorar la variedad de situaciones y de las personas que trabajan en la agricultura urbana buscando encontrar la forma de intregacion que sea mas felexible en el proceso de planeamiento urbano en Portugal y en Brasil. Asi como, hacer llegar ideas a las motivaciones actuales de los agricultores urbanos y sus ambiciones en relacion al futuro del espacio urbano. En el caso de Brasil, la búsqueda de elementos de comparación que apuntan a las características de las áreas donde la agricultura aparece en algunas ciudades brasileñas, sus programas de políticas públicas y la relación

con los ciudadanos de los resultados interesantes y promisores. Es urgente pensar una nueva forma de entendimiento para tratar la situación social de las dos apis. Hacer mas fuerte las organizaciones sociales que nacieron en la web y tambien las asociaciones de vecionos de los barrios para crear vínculos y las acciones que se agrupan con la agricultura urbana una realidad urbana y un componente de la infraestructura verde sustentable.

PALAVRA CHAVE: Sustentabilidade - Agricultura - Infraestrutura 


\section{INTRODUÇÃO}

Nas décadas anteriores, grande parte da infraestrutura urbana foi construída sem muita preocupação com seus impactos na aparência e no meio cultural de uma cidade. $O$ conceito de infraestrutura foi ampliado para integrar também a demanda por áreas verdes urbanas.

A infraestrutura urbana modernista-funcionalista do século XX reflete o pensamento de eficiência unilateral e depende de materiais e desempenho intensivos em energia (National Academy Press, 1986). Em vez disso, deve empregar uma "infraestrutura verde" que ofereça um conjunto diverso e amplo de serviços de ecossistemas biofísicos e culturais que contribua para a sustentabilidade urbana, assegurando que a redundância de infraestrutura constrói a resiliência urbana - a capacidade de absorver perturbações e se recuperar, mantendo essencialmente a mesma função, estrutura, feedbacks e, portanto, identidade (Walker et al., 2006). "Em essência, sugere abandonar a busca de uma solução única e adequada, com capacidade e flexibilidade suficientes nos sistemas para que eles possam recuperar e evoluir positivamente de perturbações" (SELMAN, 2012).

A infraestrutura verde é definida como "sistemas integrados espacial e funcionalmente e redes de paisagens protegidas apoiadas por infraestruturas protegidas, artificiais e híbridas de paisagens construídas que fornecem ao ecossistema múltiplos e complementares ecossistemas e paisagens em apoio da sustentabilidade" (AHERN, 2007).

Articular os serviços ecossistêmicos fornecidos pela infraestrutura verde é um tema de pesquisa emergente (Landscape Architecture Foundation 2014). Para os planejadores urbanos, há uma oportunidade sem precedentes no planejamento e na concepção da infraestrutura verde, tanto em contextos urbanos desenvolvidos quanto em desenvolvimento.

As cidades emergentes e em desenvolvimento do mundo têm, portanto, a oportunidade única de "fazer a coisa certa na primeira vez" e "ultrapassar" a fase modernista / industrial de infraestrutura industrial monofuncional, de baixo desempenho e insustentável - e começar de novo com um ambiente multifuncional orientado a serviços ecossistêmicos de infraestrutura verde. As intervenções de agricultura urbana no Brasil e em Portugal exploram uma série de modelos de trabalho com moradores de empreendimentos urbanos informais.

A infraestrutura híbrida ou paisagística integra-se com sistemas baseados em ecossistemas para fornecer múltiplas funções (FHWA 2006). Seu custo pode variar, dependendo do contexto e função.

Infraestrutura é uma abordagem de desenvolvimento protetor ou pré-urbano que é apropriada para paisagens periféricas e urbanas marginais para manter a integridade ecológica funcional (BENEDICT E MACMAHON, 2006).

Como mencionei antes, a agricultura urbana é "naturalmente" parte da infraestrutura verde. A agricultura urbana é um termo relativamente novo para uma grande e complexa área de horticultura científica. Em termos gerais, a agricultura urbana é o estudo das interações entre a 
administração da cidade de alimentos e sua preocupação com o uso funcional das plantas para manter e melhorar o ambiente urbano (TUKEY, 1983).

Como afirma Tardin (2008, p.54):

[...] a agricultura urbana, muitas vezes é diretamente relacionada à identidade de um lugar, normalmente ocupa espaços que frequentemente sofrem a pressão da urbanização, em particular, quando se encontram em condições de produção não lucrativas. No entanto, incentivar a agricultura no território representa uma oportunidade para recreação, educação ambiental, criação de empregos, condições de produção e comércio para pequenas produções urbanas e manutenção do espaço livre a baixo custo.

\section{OBJETIVO}

O objetivo deste artigo é explorar a integração espacial e a integração de políticas da agricultura urbana, tanto em Portugal como no Brasil, utilizando exemplos ilustrativos que expõem as questões em jogo no planejamento urbano e no processo de produção final do espaço público.

\section{METODOLOGIA}

(A) Marco de atuação dos governos nacionais e locais do Brasil e de Portugal na implementação de políticas públicas em infraestrutura verde e da agricultura urbana assim como os principais projetos em andamento. Comparação das duas realidades. (B) $\mathrm{O}$ estudo de casos: os espaços verdes urbanos na legislação e na prática de ambos os países. (C) Impacto na estrutura periurbana da construção de infraestrutura verde em Lisboa e em Passo Fundo/RS. (D) Análise da participação da comunidade e dos interessados na agricultura urbana como sendo de fundamental importância para o planejamento, projeto e manutenção da infraestrutura verde. (E) Análises mais estratégicas e abrangentes no tempo e no espaço, para que efetivamente as soluções contribuam para as metas de sustentabilidade e não apenas resolver problemas emergenciais. (F) Pesquisar o planejamento e projeto da infraestrutura verde como um processo político que passa pela negociação com as partes interessadas, para que seja socialmente justo, e responda aos anseios e necessidades da comunidade.

\subsection{AGRICULTURA URBANA EM PORTUGAL E NO BRASIL}

Em muitos países, o público urbano está mostrando crescente interesse no meio ambiente e está desenvolvendo uma maior consciência das formas físicas e psicológicas que não apenas os espaços verdes, mas também o crescimento alimentar pode melhorar as condições urbanas. Parece inevitável que as pressões sobre as autoridades municipais aumentarão para uma agricultura mais urbana. 
Já em muitos países europeus e da América Latina, mais pessoas estão agora envolvidas em agricultura urbana do que as que estão empregadas na produção agrícola.

A agricultura urbana proporciona às cidades benefícios intangíveis derivados diretamente dos serviços ecossistêmicos - estéticos, arquitetônicos, recreativos e psicológicos -, mas também as suas funções físicas são valiosas. Mas com poucas exceções, o valor das plantas para a maioria desses propósitos não foi quantificado em qualquer extensão e pouco trabalho de pesquisa tem sido feito sobre o seu uso funcional. O lado da comodidade da agricultura urbana é diverso e disperso e com poucas exceções, não parece ter pressionado para o apoio à investigação de forma concertada.

\subsubsection{Perspectivas de Lisboa: agricultura urbana em transição}

A agricultura urbana em Lisboa mudou nos últimos anos. Durante décadas, a agricultura urbana em Lisboa foi dominada por ocupações espontâneas (ilegais) em vazios urbanos e em terras abandonadas (agrotóxicos). Foi estigmatizado como um sinal de "subdesenvolvimento" e ignorado pelas administrações municipais. Este tipo de agricultura urbana tem sido principalmente um subproduto da industrialização das áreas metropolitanas de Lisboa desde os anos 60, envolvendo populações tipicamente imigrantes de origens diferentes com fundo rural.

Não foi só até a administração municipal eleita de 2007 que a agricultura urbana foi colocada na agenda política, aproveitando o ímpeto dos movimentos sociais globais, nomeadamente para melhorar a segurança alimentar, a segurança alimentar ou o movimento "slowfood", por exemplo (PIETRYKOWSKI, 2004).

Em Portugal, desde 1999, cada Plano Diretor Municipal tem de circunscrever a Estrutura Ecológica Urbana para Lisboa. Neste contexto de revisão do Plano de Lisboa, surgiu a oportunidade para a administração se recordar da agricultura urbana à luz dos objetivos definidos para a Estrutura Ecológica Urbana. Há três perfis principais da agricultura urbana que podem ser distinguidos com base nas motivações dos agricultores urbanos: "impulsionado pela comunidade", "impulsionado pelo estilo de vida" e "impulsionado pela subsistência". A fim de transmitir a especificidade de cada perfil, foram selecionados três locais como ilustrativos de cada um: UA "comunidade-driven" no bairro de Chelas, "vida-estilo dirigido" UA no bairro Graça e "subsistência dirigida" no bairro de Oriente (Figura 1). 
Figura 1. Agricultura Urbana em Lisboa em 2011

Do topo: primeira linha - Bairro de Chelas; Segunda linha - Bairro Graça; Terceira linha - bairro Oriente.

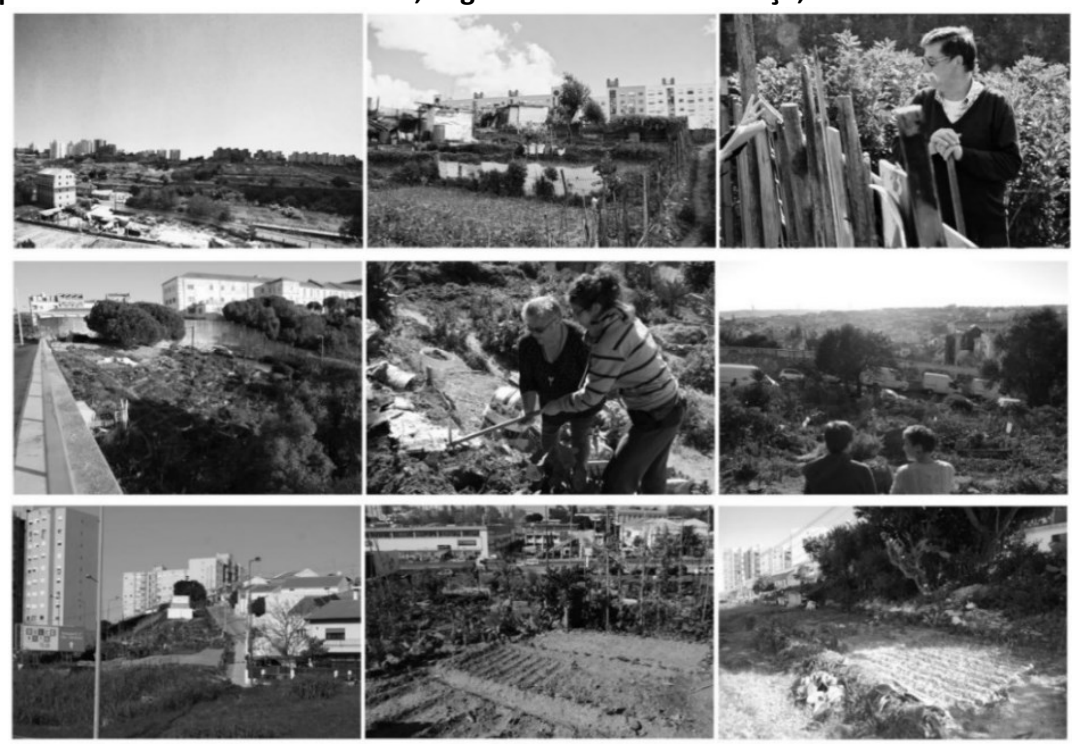

Fonte: LOUPA RAMOS

\subsubsection{Perfil dirigido pela comunidade no bairro de Chelas}

O plano urbano do bairro Chelas em Lisboa, remonta aos anos sessenta do século XX, liderado pela iniciativa da administração pública. Anteriormente, Chelas permaneceu por muitos anos uma paisagem dominada pela indústria, principalmente ao longo do córrego Chelas, e por pequenas fazendas ("Quintas") onde a produção agrícola da cidade se iniciou.

A população que se move para Chelas tem sido desde o início culturalmente muito variada, reunindo imigrantes de várias origens, em primeiro lugar, de zonas rurais profundas no interior de Portugal, mais tarde, nos anos setenta, após a Revolução dos Cravos, por migrantes das antigas colônias. Sua estrutura baseada em células habitacionais independentes, era propensa à existência de vazios urbanos e espaços intersticiais abandonados a serem ocupados por agrotóxicos. Os espaços ocupados se baseavam na auto-organização das pessoas envolvidas. 0 local é dividido em 70 parcelas individuais, reutilizando a reciclagem de materiais de resíduos que cobre uma área de cerca de 12.000 metros quadrados.

\subsubsection{Perfil de estilo de vida no bairro de Graça}

O bairro de Graça está localizado no centro histórico de Lisboa. Este local encontra-se dentro da estrutura urbana medieval, tipicamente desordenada, construída em torno do castelo da cidade ("São Jorge", datado do século II a.C.). Mas desde que, nos anos noventa, um forte investimento público em reabilitação urbana melhorou a qualidade da habitação, um intenso processo de gentrificação ganhou vida. Hoje em dia, os mais velhos partilham o bairro pacífico 
com jovens e imigrantes recém-chegados, tanto portugueses como estrangeiros.

Como há pouco espaço, este ambiente urbano é bastante incomum para a agricultura urbana. Assim, também é muito menor em tamanho (1150 metros quadrados) quando comparado ao de Chelas. Este sítio está localizado em um pequeno vazio entre um prédio e uma rua, em um terreno público vago. Temporariamente, o espaço foi mantido pelas autoridades da cidade e coberto com gramado, que não sobreviveu ao sistema de irrigação considerado pobre, sendo que, pouco depois, fora abandonado. A chamada "Horta do Monte" por seus usuários fora estabelecida pela população jovem apenas em 2010, que se uniram usando as mídias sociais ${ }^{1}$. A estrutura do sítio agrícola reflete também esta mistura cultural, uma vez que existe um lote gerido pela comunidade (partilhado por 17 pessoas) e 4 parcelas individuais menores da população local.

\subsubsection{Agricultura urbana orientada para a subsistência em Oriente}

Este bairro nos leva ao início dos anos noventa e antes disso não era realmente percebido como parte da cidade de Lisboa. Apesar da regeneração urbana dos arredores, o bairro de Oriente ainda é uma área que preserva suas características, com pouca estrutura de serviços, infraestruturas precárias e baixa qualidade do espaço público. Portanto, a agricultura urbana também aparece no espaço intersticial entre dois aglomerados residenciais consolidados: uma área de habitação única, de origem ilegal e uma área de habitação social de arranha-céus. Como em quase toda a cidade de Lisboa, este local de agricultura urbana aparece em terras abandonadas e não geridas. Neste caso, o espaço é uma área pública "não edificante" para a proteção do gasoduto que abastece a água de Lisboa a partir de um reservatório a $100 \mathrm{~km}$ ao norte, uma vez que nada pode ser feito sobre ele, nem mesmo as árvores podem ser plantadas para evitar os potenciais danos causados pelo sistema raiz à infraestrutura. Este sítio envolve 10 pessoas em uma área de 2150 metros quadrados divididos em 7 parcelas. Tudo começou apenas em 2011 devido à crise e ao desemprego. Em termos de características sociodemográficas é mais semelhante a Chelas, enquanto as motivações mais ligadas, mas há uma urgência de criação de ganhos extras para cobrir ou reduzir as despesas diárias.

\subsubsection{Enfrentando a transição}

De acordo com a administração da cidade, desde 2011, foram construídos 10 novos parques agrícolas, correspondendo a 400 parcelas (variando entre 50 e $150 \mathrm{~m} 2 \mathrm{cada}$ ). A maioria destes parques foram construídos na parte superior ou nas áreas de ocupação de posse existentes. A administração pretende implementar mais de 20 parques até 2017.

Estes parques são de propriedade da administração da cidade e alugados a agricultores urbanos em um valor por metro quadrado. Cada lote é equipado com um abrigo de

\footnotetext{
${ }^{1}$ Disponível em: www.facebook.com/hortadomonte/. Acessado em: Nov 10, 2015.
} 


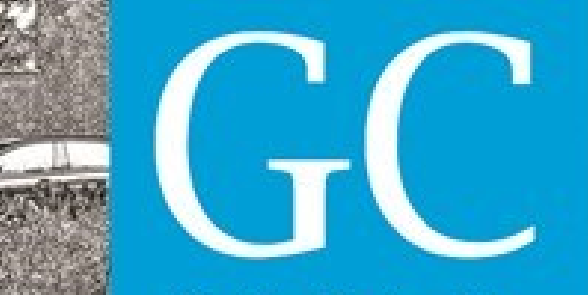

Revista Nacional de

ferramentas e está ligado a instalações públicas, nomeadamente a água, que é um fator limitante nesta região climática, como mencionado anteriormente. Os agricultores têm de seguir um regulamento, que os obriga a cultivar orgânicos e limita o que lhes é permitido fazer e plantar em cada parcela, bem como, todo o material que pode ser utilizado, por exemplo, em cercas. A cidade oferece apoio técnico aos agricultores, educando-os sobre as técnicas de agricultura biológica e introduz os recém-chegados urbanos à prática agrícola em geral. Nesta fase de transição, é possível a coexistência de um aglomerado (agora chamado de jardins de parcelas dispersas ou não organizadas). Estes também são controlados usando uma regulamentação específica menos exigente.

Os três sítios anteriormente apresentados foram revisitados em 2015 para compreender como evoluíram à luz da implementação da nova estratégia e como eles lidam com a implementação da regulamentação.

Figura 2. Sítio UA no bairro de Graça Passado (à esquerda) e atual (à direita) da UA em Graça, Lisboa

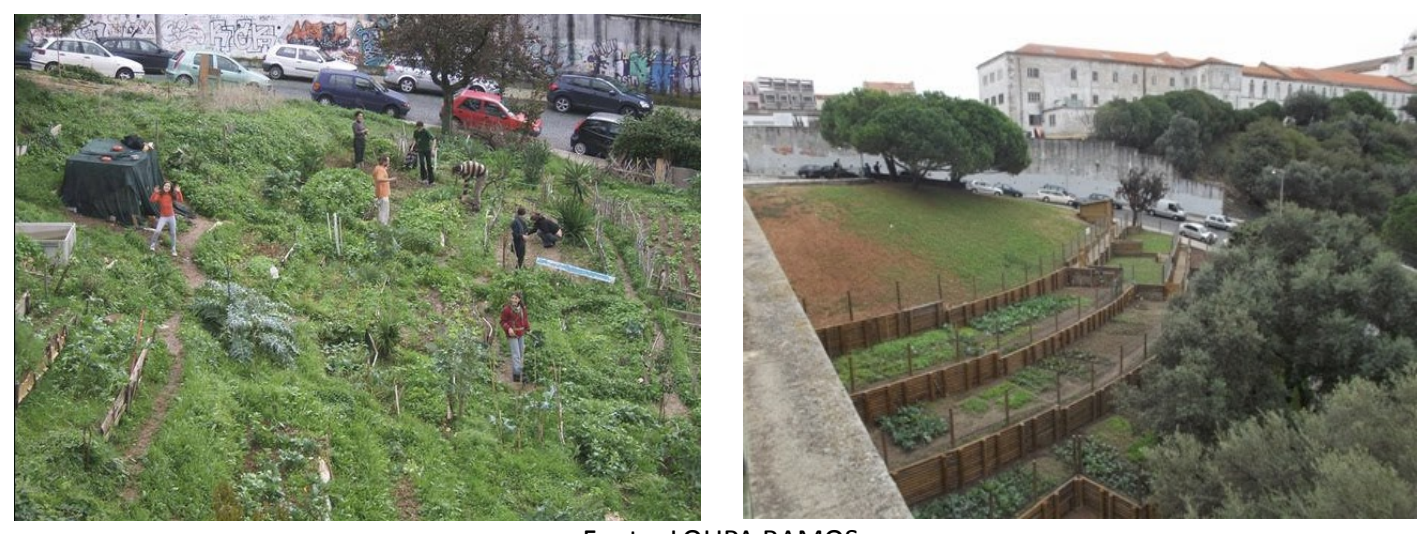

Fonte: LOUPA RAMOS

O local foi remodelado pela administração da cidade como parte de um plano para incorporálo em um parque urbano. O dia em que a UA anterior foi reduzida tornou-se notícia nacional: os jovens que se opunham ao processo foram retirados do terreno, sendo usado a força policial (Figura 2). Apenas a população local voltou para as parcelas reestruturadas ao lado do parque. O local da UA no bairro de Oriente permanece inalterado. Em frente aos locais de Chelas ou Graça a terra não é pública. Como pertence à empresa que entrega água em Lisboa (EPAL), não tem de seguir o regulamento posto em prática pela administração municipal. Os agricultores mostraram satisfeitos mesmo sem a presença de redes de infraestrutura urbana como a rede de abastecimento de água, ou sem um abrigo contra intempere ou um espaço para guardar as ferramentas, sendo obrigados a transportar todas os seus materiais de trabalho e a sua produção para a moradia de uso permanente. 


\subsection{A AGRICULTURA URBANA NAS CIDADES BRASILEIRAS}

Já em muitos países da Europa e da América Latina, mais pessoas estão agora engajadas na agricultura urbana para fins de cultivo doméstico do que para a produção agrícola. Enquanto a Europa se confronta com a redução dos excedentes de alimentos e a procura total de alimentos não é esperado aumento significativo, no Brasil, os aspectos funcionais da produção alimentar continuará a aumentar em importância.

Em 2015, o Ministério do Desenvolvimento Social e Combate à Fome (MDS) publicou uma lei de apoio a projetos de Agricultura Urbana e Periurbana ${ }^{2}$. A população urbana vulnerável de 42 cidades brasileiras poderá se beneficiar de terrenos agrícolas para produzir colheitas e comercializá-los com o apoio do MDS que passará a investir US $\$ 300$ milhões. O MDS recebeu 107 registros e qualificou 42. A maioria dos aceitos estão localizados na região do Nordeste.

\subsubsection{A agricultura urbana em São Paulo}

Em São Paulo, a agricultura urbana ativista melhorou sua organização nos últimos anos. Nisso, as redes sociais desempenham um importante papel. Como no caso do bairro Graça em Lisboa, também aqui, o grupo "Hortelões" fora criado em 2011 no Facebook. Hoje conta com quase 25 mil seguidores. São pessoas de todo o Brasil que trocam experiências e discutem a produção de alimentos na cidade. A Horta das Corujas foi a primeira que resultou desse envolvimento coletivo, na praça Dolores Ibarruri, região de Vila Madalena. O local abrange uma área de $800 \mathrm{~m}^{2}$ com culturas diversas e tem acesso a água potável. Horta é aberto a todos com uma pequena cerca para impedir a entrada de cães. Recebeu apoio do Município de Pinheiros (Figura 3).

\footnotetext{
${ }^{2}$ Disponível em: www.mds.gov.br/seguranca-alimentar .Acessado em: Nov 9, 2015.
} 


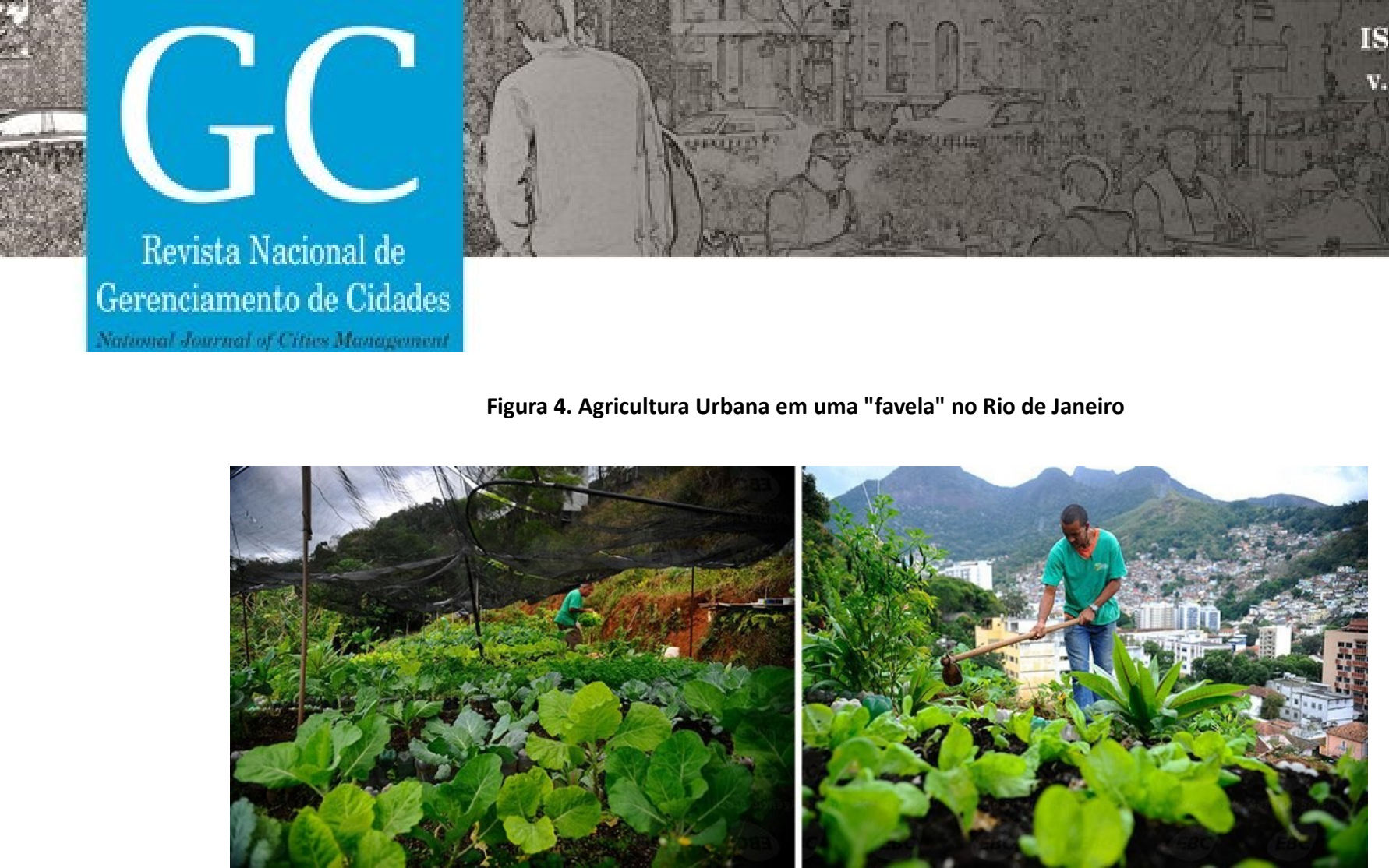

Fonte: http://www.rio.rj.gov.br/smas/Afhortascomunitarias.shtm, 2015

Agricultura urbana é implementada em áreas públicas da cidade ou os vazios sob linhas de transmissão de energia. A produção divide-se da seguinte forma: 50\% destinam-se a escolas e creches da rede municipal e famílias desprovidas indicadas pelas associações de habitantes; excessivamente $50 \%$ são vendidos para gerar renda adicional e para adquirir o equipamento pequeno ser usado em uma fazenda urbana apropriada. A administração da cidade fornece sementes, uniformes, equipamentos de proteção individual, material de mão de obra na cultura orgânica, equipamentos e fertilizantes.

Como Mancebo discutido em um artigo recente (2015), uma cidade não se origina da vontade única e habilidade de arquitetos, planejadores, agrimensores e políticos. Diferentemente do frenético cronograma e das reações diretas a qualquer oposição, os eleitos e planejadores, guiados por seus próprios interesses de curto prazo (as próximas eleições, o cumprimento dos prazos de construção etc.), impõem às políticas urbanas.

Os resultados mostram, que não há um tipo ou perfil de Agricultura Urbana, mas uma variedade que eventualmente vai muito além do considerado neste artigo.

\section{DISCUSSÃO: ENFRENTAR DESAFIOS}

E, como inicialmente proposto, uma melhor compreensão da diversidade dessas iniciativas de agricultura urbana pode estabelecer a base para sua melhor integração no planejamento e concepção urbana. Na seção anterior ilustramos a diversidade de uma vasta gama de tipologias de agricultura urbana tanto em Portugal como no Brasil. Estes variam de acordo com as motivações das pessoas envolvidas, a forma como os sítios UA se inscrevem no tecido urbano e o modelo de governança utilizado. As motivações revelaram-se difusas e dinâmicas, o que significa que cada local pode se juntar a pessoas com motivações diferentes, que a motivação para se engajar pode mudar ao longo do ciclo de vida de uma pessoa e que cada pessoa pode não ser motivada por uma única motivação. 
A governança depende da integração de políticas, significando como a Agricultura Urbana é valorizada e inscrita em documentos de política; e os arranjos de todos os atores sobre a gestão dos sítios (por exemplo, agricultores, proprietários de terras e autoridades públicas).

Em Portugal, a política de Agricultura Urbana é definida por cada administração da cidade individualmente e integrada nos planos urbanos como eles veem mais apto. Em Lisboa, o novo Plano Diretor prevê que a ocupação seja consolidada como "espaços verdes para recreação e produção" em "parques agrícolas" incorporados em parques urbanos. A administração da cidade faz isso usando uma abordagem de cima para baixo e impondo regulação / controle estrito na agricultura urbana. Isso é possível somente em terrenos públicos. Outras cidades como o Porto seguiram uma política diferente, apoiando os sítios da UA emergentes, mas não os integrando nos documentos de política ou de planejamento. Também no Brasil, não existe uma política nacional ou regional para enquadrar a agricultura urbana. Cada cidade é autônoma, permitindo-lhes executar programas específicos como no Rio de Janeiro. Dentro deste quadro institucional, o poder dos agricultores varia. A lavoura de posse utiliza tipicamente uma abordagem de baixo para cima, onde um grupo de pessoas se reúnem e organizam-se sobre como usar um pedaço de terra. Como mostra o caso de Lisboa, com o aumento da integração política, o poder desloca-se para a administração pública, fazendo com que os agricultores se vejam como "jardineiros não remunerados" (Fazendeiro no Parque Quinta da Granja, Lisboa) para a administração municipal. Os produtores de estilo de vida, como os de São Paulo ou do bairro de Graça (Lisboa), não combinam com esse modelo de governança, pois pretendem fazer uma declaração política.

Para a administração da cidade de Lisboa, a integração da UA no planejamento e concepção urbana acompanha a abordagem de planejamento baseado no positivismo que se baseia no "espaço de domar" através da definição de "ordenamento e controle" das leis espaciais (Davoudi, 2012: 432). Assim, a agricultura e os agricultores precisavam ser "domesticados" também e colocados em parques. Alguns agricultores veem nos parques agrícolas a vantagem da existência de infraestruturas, mas também as desvantagens de controle pelas autoridades públicas, a sua exposição pública aos utilizadores do parque urbano que são capazes de caminhar ao longo das parcelas e pouca proteção contra o vandalismo. Esta exposição pública, mesmo que desprezada pelos produtores, tem um alto valor educacional para a população urbana, levando-os a um interesse crescente pela observação dos processos naturais e da produção de alimentos, dos quais foram alienados. Divergindo destes dois modelos existentes, mais recentemente, uma associação local administra um "parque agrícola" ${ }^{3}$. Ele está localizado ao lado de um parque urbano, mas não parte do seu design. Todas as parcelas são protegidas atrás de cercas altas, com acesso apenas aos agricultores. Apesar de chamarem a associação de "eles" mostrando que não se sentem envolvidos, os agricultores reconhecem que a gestão é feita em seu próprio interesse e este modelo de governança mostra um alto potencial para construção de comunidades.

\footnotetext{
${ }^{3}$ Disponível em: http://avaal.org/apresentacao/. Acessado em: Nov 12, 2015.
} 


\section{CONCLUSÃO}

Sustentabilidade Infraestrutura urbana verde incluem:

\section{- Desenvolver um planejamento urbano eficaz e integrado.}

A infraestrutura urbana é intensiva em capital e as instalações precisam ser continuamente melhoradas e expandidas através de programas equilibrados de planejamento baseado na demanda para a extensão de serviços para atender às crescentes populações e necessidades urbanas.

O planejamento urbano efetivo exige uma mudança mental completa, todas as formas de infraestrutura precisam ser consideradas e planejadas para além das atuais limitações de uma abordagem setorial, para fornecer um veículo propício para a mudança e desenvolvimento da sociedade. As novas abordagens e tecnologias de planejamento apoiarão o progresso na necessidade de reduzir os custos unitários da provisão de infraestrutura, melhorando a eficiência e a qualidade, assegurando que os serviços estejam alinhados com os planos urbanos e planejem uma expansão ótima da infraestrutura para apoiar o processo de urbanização. As intervenções de infraestrutura e serviços têm um forte impacto na forma da cidade e no desenvolvimento da cidade e, portanto, precisam estar ligadas a um planejamento urbano global e estratégias de desenvolvimento da cidade, moldando um futuro sustentável e equitativo que aborde os direitos das comunidades. Melhorar a implementação coordenada da agricultura urbana (Habitat III, UN, 2015).

Além do processo de planejamento, é necessário garantir que a agricultura urbana seja desenvolvida e implementada através da compreensão dos ativos, conhecimentos e instituições de infraestrutura. Além disso, é necessário o reconhecimento e a compreensão da interdependência crítica entre todas as esferas de governo. Isto é particularmente relevante para áreas metropolitanas onde a fragmentação cria oportunidades perdidas para eficiências de prestação de serviços; e renda regional e desigualdades de nível de serviço. Estão a surgir mecanismos de coordenação: cooperação intermunicipal, incentivos legais para cooperação, agências de planejamento e desenvolvimento, acordos de partilha de custos para a prestação de serviços em todo o metropolitano, fundos de desenvolvimento metropolitano, acordos fiscais coordenados, financiamento de agrupamentos e melhor articulação entre programas nacionais e locais e políticas para garantir a eficiência e reduzir o desequilíbrio.

\section{- Desenvolver novos modelos de negócio e parcerias estratégicas.}

A rápida urbanização aumentou o alcance e a complexidade da prestação de serviços. São necessários agora novos modelos de negócios para integrar os pontos fortes e as capacidades do setor público, das empresas privadas, das ONGs e das Organizações 
Comunitárias. Novas abordagens são particularmente necessárias em setores como a drenagem urbana, saneamento, resíduos sólidos, mobilidade, abastecimento de energia limpa, agricultura urbana e prestação de serviços aos assentamentos informais.

Embora os governos dos países em desenvolvimento geralmente forneçam, possuam e operam todas as infraestruturas, existem abordagens alternativas que são eficazes na prestação de serviços e na agricultura urbana. Essas alternativas abordam a necessidade de novos modelos de negócios, como o retorno financeiro sobre o aumento do valor da terra proporcionado por novas infraestruturas, infraestruturas verdes e sistemas de garantia de investimentos.

A infraestrutura verde é uma abordagem de investimento de baixo custo, e muitas vezes de alto retorno, que tem sido utilizada com grande sucesso em muitas cidades do mundo. Particularmente no que se refere ao setor privado, o desenvolvimento e a oferta de sistemas de garantia de investimento para atrair o investimento privado e para reforçar a capacidade dos governos para fazer os necessários arranjos legais e contratuais alinhados com a capacidade de regular e gerir as entidades privadas que fornecem os serviços, oferecem benefícios e oportunidades viáveis. Essas abordagens têm a vantagem adicional de liberar a capacidade do governo de empreender redes e sistemas totalmente integrados de planejamento de infraestrutura verde que assegure ainda que a validação vital de baixo para cima desse planejamento seja implementada.

A infraestrutura verde não é uma opção, é parte integrante do Plano Mestre Urbano e será dobrado em cada projeto. A implementação de infraestruturas verdes será na maioria das vezes de natureza cirúrgica na vasta gama de projetos individuais realizados diariamente. $\mathrm{E}$ a agricultura urbana é uma parte importante da infraestrutura verde e representa muito bem a categoria de projetos individuais que realiza diariamente.

Além de satisfazer a necessidade dessa ordem de trabalho específica, os designers encontrarão maneiras de implementar infraestrutura verde. Embora a reconstrução do direito de passagem em plena rua ofereça a melhor situação para implementação, nem sempre é possível. No entanto, algo pode ser feito em cada projeto.

Uma observação merece destaque: a agricultura urbana para ter êxito, no projeto, ela deve ser considerada em pequena escala produtiva. Reconhecer que este tipo de prática tem mais inclinação educacional e ambiental do que a oferta potencial, mas para ganhar escala de produção, o estímulo da gestão pública é essencial. As casas e empresas que deveriam ter baixado o Imposto de Propriedade no caso de compostarem seus resíduos orgânicos. Outra ideia seria a distribuição de mudas em estufas municipais orgânicas (atualmente desativadas) para agricultores periurbanos e inclusão de horticultura no currículo das escolas.

A poluição urbana do jardim é um problema sério que muitos jardineiros entusiásticos não fazem exame na consideração. Antes de algum plano em seu jardim urbano, ter tempo para pensar sobre os efeitos de poluição muitos em jardins da cidade. 
No contexto do conceito proposto por Bohn e Viljoen (2005) sobre a CPUL (Paisagem Urbana Produtiva Contínua), a agricultura em áreas urbanas é integrada num quadro mais amplo de infraestruturas verdes em espaços designados num plano de zoneamento. Esta natureza espontânea é de alto valor em termos de sentido de lugar (Andersson et al., 2007) e de construção de comunidades, uma vez que envolve a participação direta de moradores da cidade que gerenciam seus ambientes urbanos (Travlaine e Hunold, 2010). Mais recentemente, esses espaços tornaram-se também uma arena para o ativismo político (MÜLLER, 2011).

Não podem ser separados de seu contexto sociopolítico mais amplo ou das múltiplas formas contrastantes e sobrepostas que as pessoas usam, valorizam e percebem (Lefebvre, 1991). Central para este entendimento é que o espaço, e, portanto, o espaço público resulta de processos sociais complexos nos quais uma grande variedade de forças e atores interagem, combinam, conflitam e oprimem, para determinar como uma área urbana se desenvolve (MASSEY 2005; CHILEERI 2013).

\section{REFERÊNCIAS BIBLIOGRÁFICAS}

AHERN, J. (2007). Green infrastructure for cities: The spatial dimension. In Cities of the Future:Towards Integrated Sustainable Water and Landscape Management,. V. Novotny and P. Brown (Eds.), 267-83. London: IWA.

AMERICAN SOCIETY OF CIVIL ENGINEERS. (2013). Restore and improve urban infrastructure. Disponível em: http://www.asce.org/reportcard/2013. Acessado em: 21/11/2014

BENEDICT AND MCMAHON 2006; BENEDICT, M. A. and MCMAHON, E. T. (2006). Green Infrastructure: Linking Landscapes and Communities. Washington: Island Press.

BRUCE PIETRYKOWSKI (2004) You Are What You Eat: The Social

Economy of the Slow Food Movement, Review of Social Economy, 62:3, 307-321,

FAO (Food and Agriculture Organization of the United Nations) 2014. Growing greener cities: FAO programme for urban and peri-urban horticulture

Disponível em: (http://www.archdaily.com.br/br/623385/as-10-cidades-latino-americanas-lideres-em-agriculturaurbana-segundo-a-fao. Acessado em: Nov 12, 2015.

FHWA (2006). U.S. Federal Highway Administration, FHWA (2006). Eco-logical: An Ecosystem Approach to Developing Infrastructure Projects. Disponível em: http://www.environment.fhwa.dot.gov/ecological/ecological.pdf. Acessado em: Maio 18, 2014.

Habitat III, UN, Task Team (2015). Issue paper 8: Urban and spatial planning and design.

Hortas das Corujas

Disponível em: https://hortadascorujas.wordpress.com/Acessado Acessado em: Nov 10, 2015.

Landscape Architecture Foundation (2014). Landscape Performance Series.

Disponível em: http://www.lafoundation.org/research/landscape-performance-series/. Acessado em: Fev 5, 2015. 
MANCEBO F., 2015. Insights for a Better Future in an Unfair World - Combining Social Justice with Sustainability, Transitions to Sustainability. Mancebo F., Sachs I. eds,: pp. 105-116, Springer

Ministério de Desenvolvimento Social e Combate à Fome

Disponível em: www.mds.gov.br/seguranca-alimentar. Acessado em: Dez 04, 2015.

National Academy Press (1986). Engineering Infrastructure Planning and Modelling.Washington, D.C.

Newman and Jennings (2008). Cities as Sustainable Ecosystems. Principles and Practices. Washington, D.C.: Island Press.

Prefeitura Municipal e Rio e Janeiro. Disponível em: http://www.rio.rj.gov.br/smas/Afhortascomunitarias.shtm e http://www.mds.gov.br/servicos/sala-de-imprensa/galeria-de-imagens/programas/hortas-comunitarias. Acessado em: Junho 07, 2015.

Prefeitura Municipal de São Paulo

Disponível em:

http://portal.prefeitura.sp.gov.br/secretarias/relacoes_internacionais/carteira_de_projetos/gestao_urbana_e_amb iental/0002. Acessado em: Junho 07, 2015.

WALKER, B. H., J. M. ANDERIES, A. P. KINZI, and P. RYAN.( 2006). Exploring resilience in social-ecological systems through comparative studies and theory development: introduction to the special issue. Ecology and Society 11(1): 12. Disponível em: http://www.ecologyandsociety.org/vol11/iss1/art12/. Acessado em: Junho 07, 2015. 